Portland State University

PDXScholar

\title{
Identification of the Biogenic Compounds Responsible for Size-Dependent Nanoparticle Growth
}

\author{
Paul M. Winkler \\ University of Vienna \\ John Ortega \\ National Center for Atmospheric Research \\ Thomas Karl \\ National Center for Atmospheric Research \\ Luca Cappellin \\ IASMA Research and Innovation Centre \\ Hans R. Friedli \\ National Center for Atmospheric Research
}

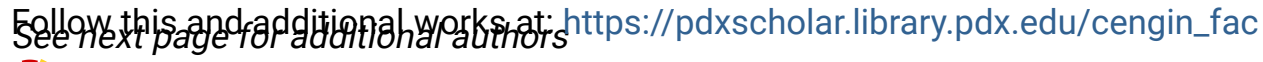

Part of the Chemistry Commons, Environmental Engineering Commons, and the Physics Commons Let us know how access to this document benefits you.

\section{Citation Details}

Winkler, Paul M., Ortega, John, Karl, Thomas, Cappellin, Luca, Friedli, Hans R., Barsanti, Kelley, McMurry, Peter H., Smith, James N. (2012). Identification of the biogenic compounds responsible for sizedependent nanoparticle growth. Geophysical Research Letters. 39(20).

This Article is brought to you for free and open access. It has been accepted for inclusion in Civil and Environmental Engineering Faculty Publications and Presentations by an authorized administrator of PDXScholar. Please contact us if we can make this document more accessible: pdxscholar@pdx.edu. 


\section{Authors}

Paul M. Winkler, John Ortega, Thomas Karl, Luca Cappellin, Hans R. Friedli, Kelley Barsanti, Peter H. McMurry, and James N. Smith 


\title{
Identification of the biogenic compounds responsible for size-dependent nanoparticle growth
}

\author{
Paul M. Winkler, ${ }^{1,2}$ John Ortega, ${ }^{1}$ Thomas Karl, ${ }^{1}$ Luca Cappellin, ${ }^{3}$ Hans R. Friedli, ${ }^{1}$ \\ Kelley Barsanti, ${ }^{4}$ Peter H. McMurry, ${ }^{5}$ and James N. Smith ${ }^{1,6}$ \\ Received 30 July 2012; revised 28 September 2012; accepted 3 October 2012; published 30 October 2012.
}

[1] The probability that freshly nucleated nanoparticles can survive to become cloud condensation nuclei is highly sensitive to particle growth rates. Much of the growth of newly formed ambient nanoparticles can be attributed to oxidized organic vapors originating from biogenic precursor gases. In this study we investigated the chemical composition of size-selected biogenic nanoparticles in the size range from 10 to $40 \mathrm{~nm}$. Particles were formed in a flow tube reactor by ozonolysis of $\alpha$-pinene and analyzed with a Thermal Desorption Chemical Ionization Mass Spectrometer. While we found similar composition in 10 and $20 \mathrm{~nm}$ particles, the relative amounts of individual species varied significantly when compared to $40 \mathrm{~nm}$ particles. Smaller particles (10 and $20 \mathrm{~nm}$ ) were characterized by enhancements in carboxylic acids and larger particles $(40 \mathrm{~nm})$ showed higher concentrations of carbonyl-containing compounds and low molecular weight organic acids. This composition change from smaller to larger size particles reflects a vapor pressure increase of the condensing vapors by 1-2 orders of magnitude indicating that the Kelvin effect plays a decisive role in the growth of biogenic nanoparticles. Citation: Winkler, P. M., J. Ortega, T. Karl, L. Cappellin, H. R. Friedli, K. Barsanti, P. H. McMurry, and J. N. Smith (2012), Identification of the biogenic compounds responsible for size-dependent nanoparticle growth, Geophys. Res. Lett., 39, L20815, doi:10.1029/2012GL053253.

\section{Introduction}

[2] The formation of nanoparticles by gas-to-particle conversion is frequently observed in the atmosphere and constitutes a major source of ambient aerosol in the submicron size range [Kulmala et al., 2004]. Potential health risks associated with the inhalation of nanoparticles as well as their expected impact on global climate through the formation of cloud condensation nuclei have led to an increased demand for understanding the underlying formation mechanisms.

\footnotetext{
${ }^{1}$ Atmospheric Chemistry Division, National Center for Atmospheric Research, Boulder, Colorado, USA.

${ }^{2}$ Now at Faculty of Physics, University of Vienna, Vienna, Austria.

${ }^{3}$ Food Quality and Nutrition Area, IASMA Research and Innovation Centre, Fondazione Edmund Mach, San Michele, Italy.

${ }^{4}$ Department of Civil and Environmental Engineering, Portland State University, Portland, Oregon, USA.

${ }^{5}$ Department of Mechanical Engineering, University of Minnesota, Twin Cities, Minneapolis, Minnesota, USA.

${ }^{6}$ Department of Applied Physics, University of Eastern Finland, Kuopio, Finland.

Corresponding author: P. M. Winkler, Faculty of Physics, University of Vienna, Vienna AT-1090, Austria. (pwinkler@ucar.edu)

(C)2012. American Geophysical Union. All Rights Reserved. 0094-8276/12/2012GL053253
}

The typical pathway currently considered is nucleation followed by growth due to condensation [Kulmala, 2003]. Recent chamber studies have shown that ambient particle formation rates can be described reasonably well by multicomponent nucleation involving sulfuric acid and ammonia or amines [Kirkby et al., 2011], but ambient levels of sulfuric acid are rarely sufficient to describe the high growth rates observed in the atmosphere [Weber et al., 1997; Boy et al., 2005; Stolzenburg et al., 2005]. Instead, the major constituents of freshly formed nanoparticles were identified to be of organic origin suggesting that organic vapors account for the rapid growth of nanoparticles [Smith et al., 2008; Wehner et al., 2005].

[3] The importance of correctly quantifying growth rates can be seen from equation (1) [McMurry and Friedlander, 1979; Weber et al., 1997],

$$
J\left(D_{P}\right)=J_{1} \cdot \exp \left(-\frac{k A_{\text {Fuchs }}}{d D_{P} / d t} \Psi\right)
$$

where the formation rate $J\left(D_{P}\right)$ of particles with diameter $D_{P}$ is related to the formation rate $J_{1}$ of $1 \mathrm{~nm}$ particles via an exponential function showing the diameter growth rate $d D_{P} / d t$ in the denominator. An expression equivalent to equation (1) was described by Kerminen and Kulmala [2002]. A Auchs is the "Fuchs surface area" [McMurry, 1983], representing coagulation efficiency, and $k$ and $\Psi$ are kinetic factors determined from theory. Accordingly, only if $d D_{P} / d t$ is sufficiently large compared to scavenging by coagulation will a significant number of $\sim 1 \mathrm{~nm}$ particles survive and grow to larger sizes. A "successful" particle formation event is thus governed by a high growth rate or a low coagulation sink.

[4] In order to better understand mechanisms responsible for nanoparticle growth we employ a Thermal Desorption Chemical Ionization Mass Spectrometer (TDCIMS) [Voisin et al., 2003; Smith et al., 2004] providing chemical speciation of size-selected particles typically in the size range between 10 and $40 \mathrm{~nm}$. In this study our focus is on laboratory generated secondary organic aerosol (SOA) formed by the ozonolysis of $\alpha$-pinene. Although this system has been widely studied due to its atmospheric relevance, little information is available on the initial steps of particle formation. Here we present new insights into properties of biogenic nanoparticles that have just outgrown the cluster regime.

\section{Experiment}

[5] A schematic of the experimental setup as well as typical operating conditions of the flow tube reactor used for SOA formation are shown in Figure S1 in Text S1 of the 


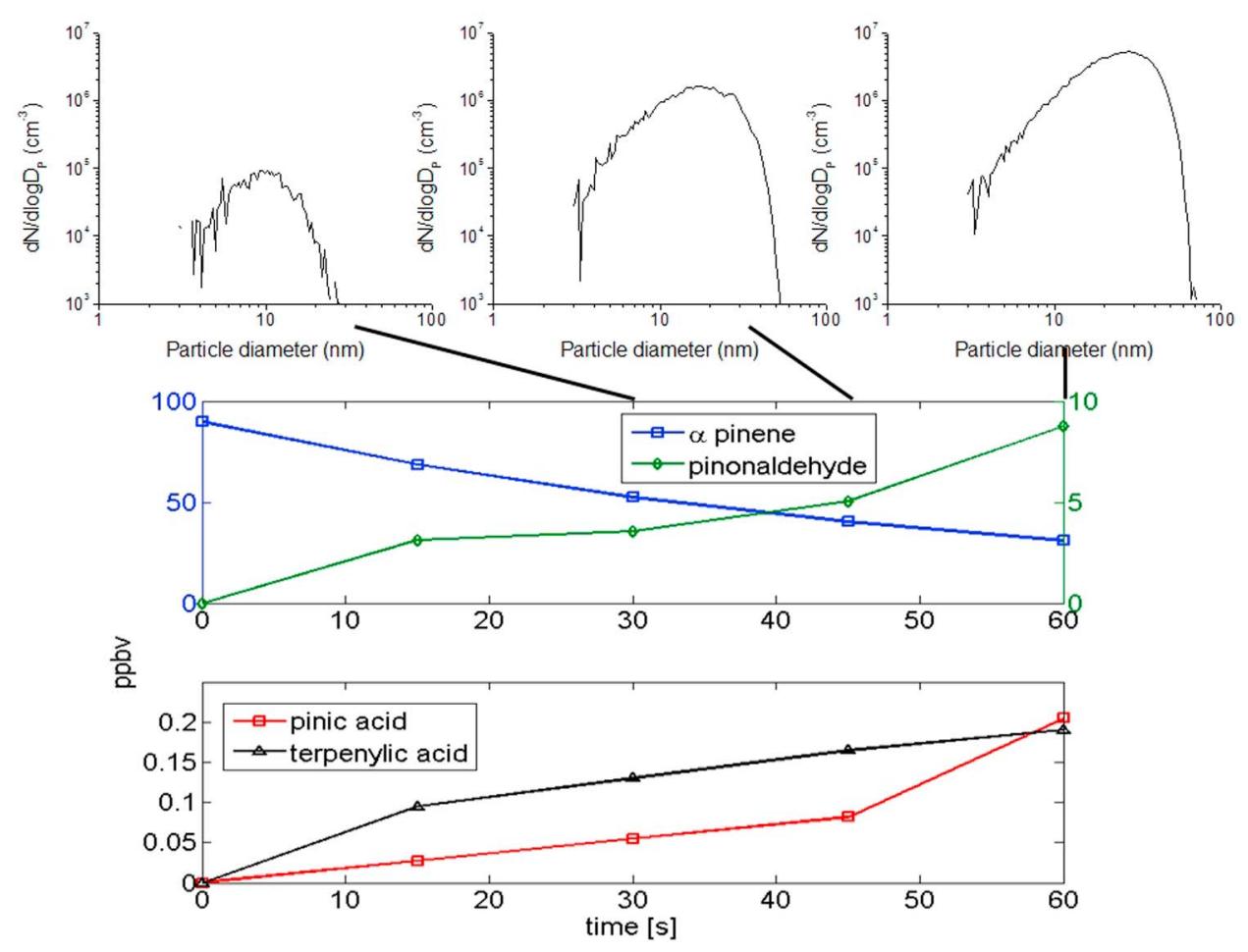

Figure 1. Selected gas-phase species concentrations at different residence times as measured with the PTR-TOF-MS. Blue shows the decrease of $\alpha$-pinene $(+137.132)$ over time whereas green shows the increase of pinonaldehyde $(+169.125)$. Black (terpenylic acid, +173.078) and red (pinic acid, +187.088) show the increase of two dominant dicarboxylic acids with time. Note the scale change in the concentration. On top are shown the size distribution data measured with the SMPS at residence times 30, 45 and $60 \mathrm{~s}$. No particles were measured at $15 \mathrm{~s}$.

auxiliary material. ${ }^{1}$ The major advantage of conducting these experiments in a flow tube as opposed to an environmental chamber is that by choosing a proper residence time, a stable aerosol with a certain size distribution and sufficiently high number concentration can be maintained for hours or even days. This allows much higher sample collection compared to chamber studies, which is essential for the characterization of $10 \mathrm{~nm}$ particle composition.

[6] A comprehensive suite of instruments was used to characterize gas-phase composition, size distribution evolution and particle chemical composition. Ozone concentration was measured using a photometric ozone analyzer [Thermo Electron, model 49]. Gas-phase volatile organic compounds (VOCs) were monitored by a Proton Transfer Reaction Timeof-Flight Mass Spectrometer (PTR-TOF-MS) [Jordan et al., 2009]. This instrument has sufficiently high mass resolution as to allow the quantitative determination of VOCs up to $m / z$ 500. Instrumental setup and calibration procedures for the PTR-TOF-MS are described in the auxiliary material. Particle size distributions were monitored using a scanning mobility particle sizer (SMPS) comprising of a nanometer differential mobility analyzer (nano DMA, TSI Inc., model 3085) and an ultrafine condensation particle counter (UCPC, TSI Inc., model 3025).

[7] The chemical composition of size-selected particles was measured using the TDCIMS. This system uses a low resolution electrostatic classification technique [McMurry

${ }^{1}$ Auxiliary materials are available in the HTML. doi:10.1029/ 2012GL053253. et al., 2009] to collect samples of aerosol nanoparticles on a metal filament and then resistively heats the filament and analyzes the desorbed gas using chemical ionization mass spectrometry. In separate but complementary experiments, a quadrupole and a high-resolution time-of-flight (HTOF) mass spectrometer were used. Quantitative analysis of the mass spectra was performed on the quadrupole system, whereas the HTOF was used to identify the exact chemical formulae of the peaks. Since the TDCIMS relies on thermal desorption of sampled aerosol in its analysis, any oligomers that may be formed in particles most likely decompose into their respective monomers [Hall and Johnston, 2012]. In reporting both HTOF-TDCIMS and PTR-TOF-MS measurements below, molecular compounds are assigned based on exact molecular composition with the caveat that neither instrument is capable of distinguishing structural isomers.

\section{Results}

\subsection{Gas-Phase Measurements}

[8] The gas-phase evolution due to the ozonolysis was measured at four different residence times $(15,30,45$ and $60 \mathrm{~s})$. Figure 1 depicts the time evolution of the precursor vapor and three reaction product ions for the first $60 \mathrm{~s}$, which are characterized by an exponential decrease of $\alpha$-pinene and reaction intermediates that increase over time. The measured decrease of $\alpha$-pinene followed a predicted evolution using the Leeds Master Chemical Mechanism (MCM) [Saunders et al., 2003], where the $\mathrm{OH}$ concentration was calculated to be on the order of $10^{8}$ molecules $\mathrm{cm}^{-3}$ (see auxiliary 
material, Figure S2). Based on this, the combined lifetime of $\alpha$-pinene due to $\mathrm{OH}$ and $\mathrm{O}_{3}$ oxidation is then calculated as $68 \mathrm{~s}$, close to what has been estimated from Figure 1. The MCM predicts RO2 levels for these experiments (ref. Figure S2) that are higher than those found in the atmosphere; if accurate, this can affect the identity and yields of reaction products [Jenkin, 2004]. For this simple system the PTR-TOF-MS detected more than 450 ions due to oxidation chemistry. While a complete interpretation of the mass spectrum is beyond the scope of this paper we focus on key species that are known to be produced during the oxidation of $\alpha$-pinene. Figure 1 shows that during the course of the experiment pinonaldehyde concentrations increased to about 9 ppbv while the dominant organic acids, pinic acid and terpenylic and/or cis-norpinonic acid, increased to about $0.2 \mathrm{ppbv}$ under $\mathrm{NO}_{\mathrm{x}}$-free conditions. These organic acids have been identified as major constituents in organic aerosol [Claeys et al., 2009] and, as shown below, also correspond to ion peaks at $m / z-171$ and 185 observed in the TDCIMS negative ion mass spectra.

\subsection{Particle-Phase Measurements}

[9] Also shown in Figure 1 is the evolution of the particle size distribution as a function of residence time. While few particles are produced during the first $30 \mathrm{~s}$, a steep increase in particle number and size is observed at $45 \mathrm{~s}$ reaction time. The latter residence time was used for particle analysis with the TDCIMS as the corresponding size distribution exhibits all sizes of interest at sufficient number concentration and coagulation effects can still be regarded negligible. After $60 \mathrm{~s}$ the peak of the size distribution appears at about $30 \mathrm{~nm}$ corresponding to a diameter growth rate of $\sim 30 \mathrm{~nm} \mathrm{~min}{ }^{-1}$. Furthermore it is notable that particles smaller than $10 \mathrm{~nm}$ appear at much lower concentrations at all residence times preventing analysis of particle sizes below $10 \mathrm{~nm}$.

\subsubsection{Aerosol Volatility and the Effects of Sampling Time}

[10] Particle composition data have been obtained for particle mobility diameters of 10, 20 and $40 \mathrm{~nm}$. For sufficient signal-to-noise ratios sampled particulate masses in the order of $10 \mathrm{ng}$ are desired. To compensate for the substantially smaller masses in the smallest particles, the collection time must be increased relative to that of larger particles. A quantitative comparison between samples of different particle sizes collected over different periods of time is only possible if the composition of the collected sample does not change during collection, e.g., by evaporation of semivolatile constituents. We therefore present results of measured composition of aerosol formed under identical flow tube conditions, but sampled for different lengths of time.

[11] As a consequence of the size distribution where $20 \mathrm{~nm}$ particles are close to the maximum of the distribution and larger $40 \mathrm{~nm}$ particles are in the tail at much lower concentration (Figure 1), both 20 and $40 \mathrm{~nm}$ diameter particles were collected for 30 minutes yielding mass loadings of about $12 \mathrm{ng}$ at each size. The much lower concentration and mass of the $10 \mathrm{~nm}$ particles necessitated collecting for 3 and 6 hours to obtain mass loadings of $\sim 3$ and $6 \mathrm{ng}$, respectively.

[12] Under otherwise identical experimental conditions, except a doubling of collection time, one would expect a doubling of the ion abundances in the mass spectrum. Figures $2 \mathrm{a}$ and $2 \mathrm{~b}$ show negative and positive ion TDCIMS spectra obtained from $10 \mathrm{~nm}$ particles collected for 3 hours.
To our knowledge, these spectra are the first reported of the composition of sub-20 nm diameter laboratory-generated SOA. The positive and negative ion mass spectra are characterized by peak series of homologous compounds, which decrease in intensity at larger $\mathrm{m} / \mathrm{z}$ due in part to decreased concentration, but also due to ion decomposition during thermal desorption and ionization as well as a decreased transmission efficiency of larger ions through the quadrupole mass spectrometer. We define the "volatility ratio" as the 6 hour mass-normalized ion abundance (backgroundsubtracted peak area divided by the collected aerosol mass) divided by the respective 3 hour mass-normalized ion abundance. If the volatility ratio is close to unity to within experimental uncertainty, the respective ion can be considered non-volatile and thus its abundance is linearly dependent upon collection time. These ions are color-coded red in Figures $2 \mathrm{a}$ and $2 \mathrm{~b}$ and have been termed "non-volatile." "Semi-volatile" ions (black) corresponded to volatility ratios of between 0.5 and 1 . Ions in blue exhibited ratios of less than 0.5 , suggesting that these are the most volatile in the recorded mass spectra and are therefore termed "volatile." From Figures $2 a$ and $2 b$ it can be seen that the negative ion spectrum contains more non-volatile ions compared to the positive ion spectrum, whereas semi-volatile and volatile ions dominate the positive ion mass spectrum. From this analysis it is clear that collection time has an impact on the measured composition, especially in the positive ion mass spectra. Thus in our analysis we shall only compare nonvolatile ions (shown in red), which are collection timeindependent, for samples collected at different aerosol sizes and over different collection times.

\subsubsection{Aerosol Composition and the Effects of Particle Size}

[13] Figure S4 in the auxiliary material shows the ratio of the mass-normalized abundance of non-volatile ions in $10 \mathrm{~nm}$ particles to that in 20 and $40 \mathrm{~nm}$ particles. If this ratio for a given ion is 1 , then that ion is present at equal concentration in both $10 \mathrm{~nm}$ and larger sized particles. The plot in Figure S4 shows relatively minor differences in the composition of 10 and $20 \mathrm{~nm}$ diameter particles, as the ratio is close to unity for all detected non-volatile ions. In contrast, the mass-normalized abundances for most ions in $10 \mathrm{~nm}$ diameter particles are approximately twice that of $40 \mathrm{~nm}$ particles (ref: Figure S4, open triangles). From this we can conclude that particles of 10 and $20 \mathrm{~nm}$ exhibit similar composition, at least for the non-volatile ions detected by the TDCIMS. However, $10 \mathrm{~nm}$ particles consist of roughly twice as much non-volatile material as there is in the larger $40 \mathrm{~nm}$ particles.

[14] Next, we investigate the specific compounds that contribute to the differences in the composition of $40 \mathrm{~nm}$ diameter particles compared to 10 and $20 \mathrm{~nm}$ diameter particles. For this analysis we directly compare the composition of $20 \mathrm{~nm}$ diameter particles to that of $40 \mathrm{~nm}$ diameter particles, since both 20 and $40 \mathrm{~nm}$ particles were sampled for the same collection time and therefore biases in the measured composition due to volatility are minimized. Figures $2 \mathrm{c}$ and $2 \mathrm{~d}$ show negative and positive ion mass spectra from $20 \mathrm{~nm}$ particles, in which the peaks are classified according to the mass-normalized ion abundance in $20 \mathrm{~nm}$ particles divided by that in $40 \mathrm{~nm}$ particles. Here, red indicates ions significantly more abundant in $20 \mathrm{~nm}$ particles, which we define as those for which the minimum value of the ion in 

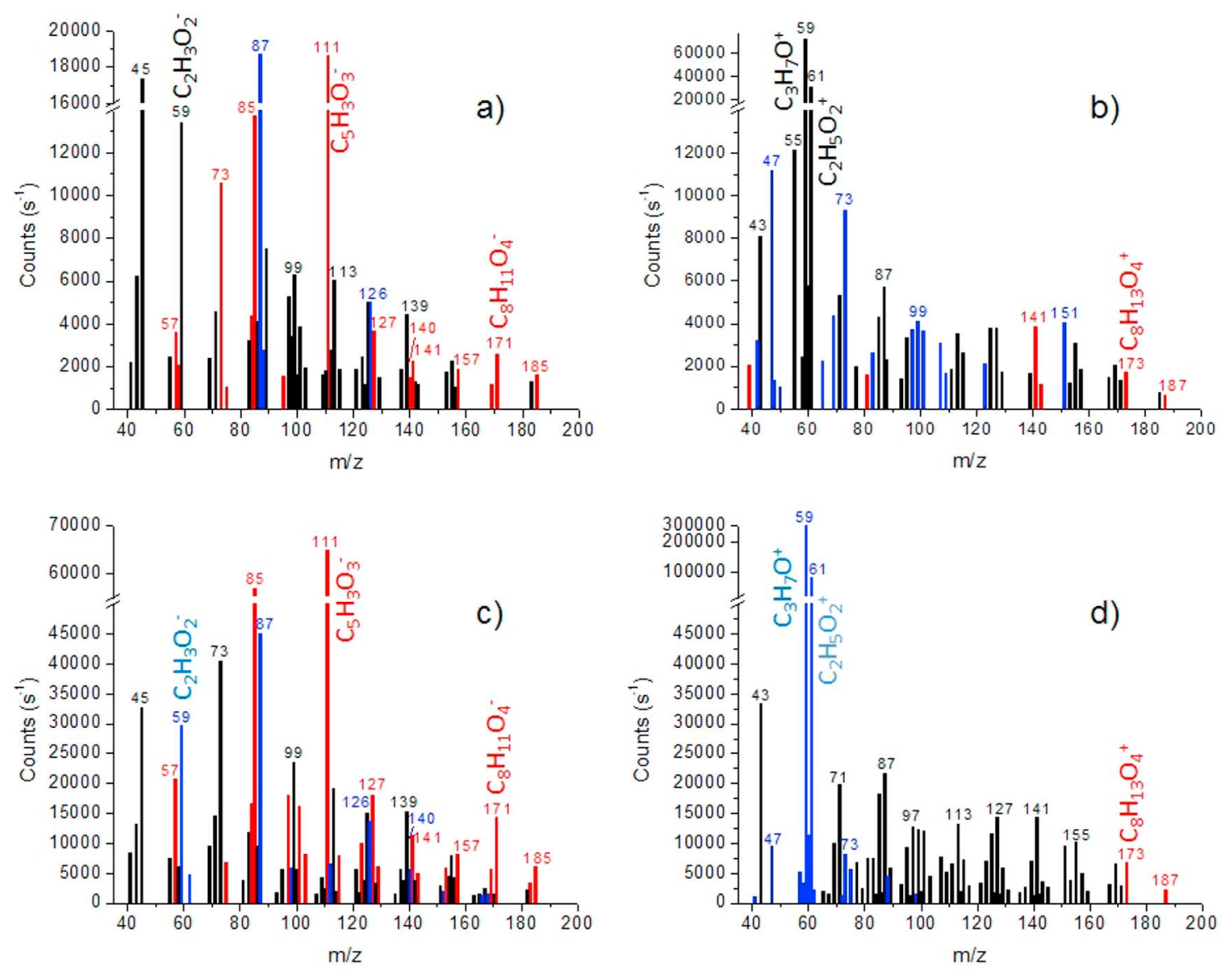

Figure 2. (a) Negative and (b) positive ion spectra from $10 \mathrm{~nm}$ particles collected for 3 hours. Mass loadings were determined as $3.1 \mathrm{ng}$ (negative mode) and $2.9 \mathrm{ng}$ (positive). Color-coding refers to different groups of volatility ratios as defined in the text. Red bars indicate "non-volatile" ions with volatility ratios close to one, blue bars refer to ratios of $<0.5$ and therefore show "volatile" ions. "Semi-volatile" ions are displayed in black and refer to volatility ratios between 0.5 and 1. Formula assignments as determined with the HTOF-TDCIMS are shown for selected ions. Also plotted are (c) negative and (d) positive ion spectra from $20 \mathrm{~nm}$ particles collected for 0.5 hours. Mass loadings were determined as $13.9 \mathrm{ng}$ (negative mode) and $12.5 \mathrm{ng}$ (positive). Color-coding refers to the behavior of certain ions when compared to the signal from the $40 \mathrm{~nm}$ particles. Red bars indicate ions that dominate in $20 \mathrm{~nm}$ particles; blue bars are ions that dominate in $40 \mathrm{~nm}$ particles. Black bars represent ions termed equal in both particle sizes.

$20 \mathrm{~nm}$ particles, after accounting for a $10 \%$ uncertainty in the collected mass, does not fall below $150 \%$ of the value for $40 \mathrm{~nm}$ particles. Plotted in blue are ions that dominate in $40 \mathrm{~nm}$ particles, which are defined as those for which the maximum value of the ion in $20 \mathrm{~nm}$ particles stays below $90 \%$ of the value for $40 \mathrm{~nm}$ particles (see also Figure S3). Ions in black did not exceed either of the chosen thresholds and are thus considered equal in both particle sizes. Different thresholds were chosen to better visualize the size dependent particle composition but do not affect the interpretation of these results.

[15] Figures $2 \mathrm{c}$ and $2 \mathrm{~d}$ clearly show different particle composition at different sizes. The negative spectrum is dominated by ions more prevalent in $20 \mathrm{~nm}$ diameter particles whereas the overwhelmingly highest ion counts in the positive spectrum indicate their prevalence in $40 \mathrm{~nm}$ diameter particles. Interestingly enough, the only two ions in the positive spectrum that appear red (higher concentration in $20 \mathrm{~nm}$ diameter particles) are the protonated counterparts of the negative, deprotonated $\mathrm{m} / \mathrm{z}-171$ (cis-norpinic and/or terpenylic acid) and -185 (pinic acid) ions [Claeys et al.,
2009; Gao et al., 2010]. Both are dicarboxylic acids and well-known constituents of $\alpha$-pinene initiated SOA and are found in even greater abundance in the negative ion spectrum. While the importance of these species in the growth of nanometer-sized particles has previously been hypothesized from measurements of larger diameter particles [Claeys et al., 2009], we provide evidence of their importance in smallest biogenic nanoparticles from direct measurements.

[16] When comparing the color-coded classifications in Figures 2a, 2b, 2c and 2d we observe that all ions with lowest volatility dominate the 10 and $20 \mathrm{~nm}$ particle composition, whereas more volatile ions coincide with the appearance of $40 \mathrm{~nm}$ particles. Furthermore it is remarkable that, with the exception of one minor ion at $\mathrm{m} / \mathrm{z}-140$, none of the ions dominating $20 \mathrm{~nm}$ particle composition (red, Figures $2 \mathrm{c}$ and $2 \mathrm{~d}$ ) fall in the category "volatile" (blue, Figures $2 \mathrm{a}$ and $2 \mathrm{~b}$ ) and vice versa. These observations are therefore consistent with one another and clearly suggest that vapor partitioning to the particle phase is size dependent. This finding is in accordance with the Kelvin equation, which states that higher vapor pressure compounds can partition into larger sized 


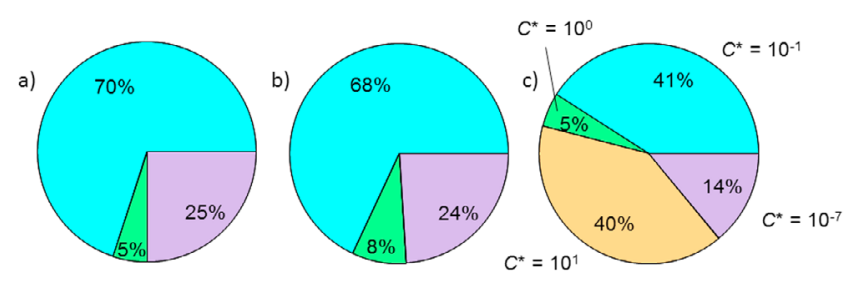

Figure 3. Modeled molar-scale composition as a function of particle size for a parameterized $\alpha$-pinene + ozone system consisting of four lumped oxidation products and one high molecular weight/low volatility product (see supplement material for model description). Size-dependent composition is shown for (a) 10, (b) 20, and (c) $40 \mathrm{~nm}$ particles. Saturation concentrations $\left(C^{*}\right)$ of the compounds are labeled in Figure 3c.

particles, whereas smaller particles require that the condensing species have a lower vapor pressure.

\subsubsection{High Resolution Particle Composition Analysis}

[17] All results on particle phase composition presented above were obtained using unit mass resolution data from a quadrupole mass spectrometer-based TDCIMS. In separate experiments we applied a High Resolution Time-of-Flight (HTOF)-based TDCIMS to the study of $20 \mathrm{~nm}$ particle composition in order to determine exact molecular formulae. Tables S1a, b present results for selected ions representative of the two categories "non-volatile" and "volatile." Among the most important ions in the negative mode, $m / z-171$ and -185 were positively identified as $\mathrm{C}_{8} \mathrm{H}_{11} \mathrm{O}_{4}^{-}$and $\mathrm{C}_{9} \mathrm{H}_{13} \mathrm{O}_{4}^{-}$, respectively. Both formulae agree with the compounds suggested by Claeys et al. [2009] and Gao et al. [2010].

[18] In the positive ion spectra, $m / z+59$ was assigned to $\mathrm{C}_{3} \mathrm{H}_{7} \mathrm{O}^{+}$, a protonated $\mathrm{C}_{3}$ carbonyl (acetone), which likely originates from fragmentation of larger molecular weight carbonyl-containing compounds during thermal desorption, chemical ionization, or ion-neutral collisions. In summary, the general picture suggests that the negative mass spectra are dominated by mono- and dicarboxylic acids, whereas the identified ions in the positive spectra include carbonylcontaining compounds as well as protonated organic acids. These molecular assignments are consistent with the species that are expected to react with TDCIMS reagent ions, i.e., $\left(\mathrm{H}_{2} \mathrm{O}\right)_{\mathrm{n}} \mathrm{H}_{3} \mathrm{O}^{+}$and $\left(\mathrm{H}_{2} \mathrm{O}\right)_{\mathrm{n}} \mathrm{O}_{2}^{-}(\mathrm{n}=0-2)$ in positive and negative ion modes, respectively.

\section{Comparison to Growth Model}

[19] The observed size dependent composition change is also supported by process level modeling of condensational growth. More specifically, the model supports the experimental results that composition is similar between 10 and $20 \mathrm{~nm}$ particles, and dissimilar between 10-20 and $40 \mathrm{~nm}$ particles. A description of the model is given in the auxiliary material. Figure 3 shows the molar-scale contribution of each model compound to predicted particle growth as a function of particle size for a 10,20 , and $40 \mathrm{~nm}$ particle (see Table S2 for description of model compounds; the saturation concentration $\left(C^{*}\right)$ for these compounds are shown in Figure 3c). The single particle growth model reproduces the experimentally-observed changing particle composition as a function of particle size, with carboxylic acids (or compounds with vapor pressures on the order of $10^{-11} \mathrm{~atm}$ or less, corresponding to $C^{*}$ values of $10^{-1} \mu \mathrm{g} \mathrm{m}^{-3}$ or less) contributing to the growth of particles down to $4 \mathrm{~nm}$ and multifunctional hydroxy-carbonyls (or compounds with vapor pressures on the order of $10^{-9} \mathrm{~atm}$, or a $C^{*}$ of $10^{1} \mu \mathrm{g} \mathrm{m}^{-3}$ ) contributing to particles $>30 \mathrm{~nm}$. Highervolatility oxidation products are typically formed in greater yields than lower-volatility products, thus once such compounds can contribute to growth as predicted by the Kelvin effect, they will become the dominant species contributing to and accelerating growth. The predicted growth rates for a reacted $\alpha$-pinene concentration of $10 \mathrm{ppb}$ were $32 \mathrm{~nm} \mathrm{~min}^{-1}$ for a $5 \mathrm{~nm}$ particle, $39 \mathrm{~nm} \mathrm{m^{-1 }}$ for a $10 \mathrm{~nm}$ particle, and $58 \mathrm{~nm} \mathrm{~min}{ }^{-1}$ for a $40 \mathrm{~nm}$ particle. This increase in the predicted growth rates between the 10 and $40 \mathrm{~nm}$ particles is due to the contribution of oxidation product "3" to growth (see Table S2). Notably, the calculated growth rates are in good agreement with the experimentally observed rate of $\sim 30 \mathrm{~nm} \mathrm{~min}{ }^{-1}$. Product 3 has a Kelvin-corrected vapor pressure of $3 \times 10^{-9} \mathrm{~atm}$ over a $40 \mathrm{~nm}$ particle; that vapor pressure increases to $7 \times 10^{-9}$ atm over a $10 \mathrm{~nm}$ particle. The relatively volatile $\alpha$-pinene oxidation products, as represented by Products 3 and 4 , are unable to overcome the Kelvin effect at particle sizes $<30 \mathrm{~nm}$ and thus do not contribute to particle growth. However, due to their relatively high abundance, once such compounds do overcome the Kelvin effect (e.g., at $30 \mathrm{~nm}$ for Product 3), as demonstrated here, measured and predicted growth rates and composition change significantly. Thus the consistent picture that emerges when comparing both experimental and modeling results is that the Kelvin effect plays a substantial role in determining particle growth rates and composition.

\section{Conclusions}

[20] Size-selected biogenic nanoparticles formed from the ozonolysis of $\alpha$-pinene were directly analyzed for their chemical composition using the TDCIMS. While particles with mobility diameters of 10 and $20 \mathrm{~nm}$ appear to have similar composition, a composition change is clearly observed for particles with diameters of $40 \mathrm{~nm}$. The smaller particles were enriched in mono- and dicarboxylic acids, while larger particles showed higher concentrations of carbonyl-containing compounds and low molecular weight organic acids. The particle composition change between 20 and $40 \mathrm{~nm}$ particles is thus indicative of a growth process governed by the condensation of compounds of steadily increasing vapor pressures. This finding is confirmed by the growth model suggesting a vapor pressure increase of the respective compounds from $\leq 10^{-11}$ atm to $\sim 10^{-9}$ atm. Accordingly, the growth of biogenic nanoparticles is highly sensitive to the Kelvin effect confirming the early work done by Heisler and Friedlander [1977].

[21] A comparison of selected compounds detected in the gas phase (Figure 1) to the aerosol phase provides insights into the mechanisms of aerosol growth due to organic compounds. The ions $m / z+173$ and +187 are observed in the gas phase using the PTR-TOF-MS, and in addition these gas phase species increase with reaction time. Significantly, ions at the same $\mathrm{m} / \mathrm{z}$, as well as the deprotonated counterparts to these ions, are observed in TDCIMS spectra as mentioned previously. One possible interpretation for this observation is 
that these species form in the gas phase and directly condense onto newly formed particles.

[22] For the conditions used in the current study the growth due to this mechanism is very fast, with growth rates in the order of thousands of nanometers per hour $\left(\sim 30 \mathrm{~nm} \mathrm{~min}^{-1}\right)$. This rapid growth may be the reason why we don't see substantial amounts of particles below $10 \mathrm{~nm}$. Whether this is of immediate atmospheric relevance remains to be shown as the concentrations in the flow tube were 1-2 orders of magnitude above ambient levels. However, for a better understanding of nanoparticle growth processes, future research should focus on highly time-resolved particle size measurements.

[23] Acknowledgments. This work was supported by the Austrian Science Fund (FWF): J3198-N21 and by US DOE grant DE-SC0006861. J.N.S. acknowledges funding from the Finnish Academy grant 251007 and US NSF grant 0919317. The National Center for Atmospheric Research is supported by NSF.

[24] The Editor thanks two anonymous reviewers for assistance evaluating this paper.

\section{References}

Boy, M., et al. (2005), Sulphuric acid closure and contribution to nucleation mode particle growth, Atmos. Chem. Phys., 5, 863-878, doi:10.5194/ acp-5-863-2005.

Claeys, M., et al. (2009), Terpenylic acid and related compounds from the oxidation of $\alpha$ pinene: Implications for new particle formation and growth above forests, Environ. Sci. Technol., 43, 6976-6982, doi:10.1021/es9007596.

Gao, Y., W. A. Hall, and M. V. Johnston (2010), Molecular composition of monoterpene secondary organic aerosol at low mass loading, Environ. Sci. Technol., 44, 7897-7902, doi:10.1021/es101861k.

Hall, W. A., III, and M. V. Johnston (2012), The thermal stability of oligomers in alpha-pinene secondary organic aerosol, Aerosol Sci. Technol., 46, 983-989, doi:10.1080/02786826.2012.685114.

Heisler, S. L., and S. K. Friedlander (1977), Gas-to-particle conversion in photochemical smog: Aerosol growth laws and mechanisms for organics, Atmos. Environ., 11, 157-168, doi:10.1016/0004-6981(77)90220-7.

Jenkin, M. E. (2004), Modeling the formation and composition of secondary organic aerosol from $\alpha$ - and $\beta$-pinene ozonolysis using MCM v3, Atmos. Chem. Phys., 4, 1741-1757, doi:10.5194/acp-4-1741-2004.

Jordan, A., et al. (2009), A high resolution and high sensitivity protontransfer-reaction time-of flight mass spectrometer (PTR-TOF-MS), Int. J. Mass Spectrom., 286, 122-128, doi:10.1016/j.ijms.2009.07.005.
Kerminen, V.-M., and M. Kulmala (2002), Analytical formulae connecting the "real" and the "apparent" nucleation rate and the nuclei number concentration for atmospheric nucleation events, J. Aerosol Sci., 33(4), 609-622, doi:10.1016/S0021-8502(01)00194-X.

Kirkby, J., et al. (2011), Role of sulfuric acid, ammonia, and galactic cosmic rays in atmospheric aerosol nucleation, Nature, 476, 429-433, doi:10.1038/nature10343.

Kulmala, M. (2003), How particles nucleate and grow, Science, 302, 1000-1001, doi:10.1126/science.1090848.

Kulmala, M., et al. (2004), Formation and growth rates of ultrafine atmospheric particles: A review of observations, J. Aerosol Sci., 35, 143-176, doi:10.1016/j.jaerosci.2003.10.003.

McMurry, P. H. (1983), New particle formation in the presence of an aerosol: Rates, time scales and sub-0.01 $\mu \mathrm{m}$ size distributions, J. Colloid Interface Sci., 95(1), 72-80, doi:10.1016/0021-9797(83)90073-5.

McMurry, P. H., and S. K. Friedlander (1979), New particle formation in the presence of an aerosol, Atmos. Environ., 13, 1635-1651, doi:10.1016/0004-6981(79)90322-6.

McMurry, P. H., et al. (2009), Sampling nanoparticles for chemical analysis by low resolution electrical mobility classification, Environ. Sci. Technol., 43, 4653-4658, doi:10.1021/es8029335.

Saunders, S. M., et al. (2003), Protocol for the development of the Master Chemical Mechanism, MCM v3 (Part A): Tropospheric degradation of non-aromatic volatile organic compounds, Atmos. Chem. Phys., 3, 161-180, doi:10.5194/acp-3-161-2003.

Smith, J. N., et al. (2004), Atmospheric measurements of sub-20 nm diameter particle chemical composition by thermal desorption chemical ionization mass spectrometry, Aerosol Sci. Technol., 38, 100-110, doi:10.1080/02786820490249036.

Smith, J. N., M. J. Dunn, T. M. VanReken, K. Iida, M. R. Stolzenburg, P. H. McMurry, and L. G. Huey (2008), Chemical composition of atmospheric nanoparticles formed from nucleation in Tecamac, Mexico: Evidence for an important role for organic species in nanoparticle growth, Geophys. Res. Lett., 35, L04808, doi:10.1029/2007GL032523.

Stolzenburg, M. R., P. H. McMurry, H. Sakurai, J. N. Smith, R. L. Mauldin III, F. L. Eisele, and C. F. Clement (2005), Growth rates of freshly nucleated atmospheric particles in Atlanta, J. Geophys. Res., 110, D22S05, doi:10.1029/2005JD005935.

Voisin, D., et al. (2003), Thermal desorption chemical ionization mass spectrometer for ultrafine particle chemical composition, Aerosol Sci. Technol., 37, 471-475, doi:10.1080/02786820300959.

Weber, R. J., et al. (1997), Measurements of new particle formation and ultrafine particle growth rates at a clean continental site, J. Geophys. Res., 102(D4), 4375-4385, doi:10.1029/96JD03656.

Wehner, B., T. Petäjä, M. Boy, C. Engler, W. Birmili, T. Tuch, A. Wiedensohler, and M. Kulmala (2005), The contribution of sulfuric acid and non-volatile compounds on the growth of freshly formed atmospheric aerosols, Geophys. Res. Lett., 32, L17810, doi:10.1029/ 2005 GL023827. 